\title{
Immobilization Stress-Induced Alterations of Monoamines in Brain of the Rat
}

\author{
Rinki Kumari ${ }^{1 *}$, Aruna Agrawal ${ }^{2}$ and G.P. Dubey ${ }^{*}$ \\ ${ }^{1}$ Junior Research Fellow under DST project and Ph.D Scholar, Department of Kriya Sharir, Faculty of Ayurveda, Institute of Medical Science, Banaras Hindu \\ University, Varanasi, Uttar Pradesh-221005, India. \\ ${ }^{2}$ Professor, Department of Kriya Sharir and Coordinator, Advanced Centre for Traditional and Genomic Medicine, Faculty of Ayurveda, Institute of Medical \\ Science, Banaras Hindu University, Varanasi, Uttar Pradesh-221005, India. \\ ${ }^{3}$ Distinguished Professor, Advanced Centre for Traditional and Genomic Medicine, Institute of Medical Science, Banaras Hindu University, Varanasi - 221 005,
} Uttar Pradesh, India.

Received: September 10, 2016; Accepted: September 13, 2016; Published: September 25, 2016

*Corresponding author: Rinki Kumari, Junior Research Fellow under DST project and Ph.D Scholar, Department of Kriya Sharir, Faculty of Ayurveda, Institute of Medical Science, Banaras Hindu University, Varanasi, Uttar Pradesh-221005, India, Email: rinkiv3@gmail.com

\begin{abstract}
Monoaminergic systems are important modulators of the responses to stress and stress may influence feeding behavior, and the involvement of monoamines in the control of food intake is well to recognize and other functions. This paper is focusing on using animal models as a stress model, a forced swimming stress was applied to rats and causes a characteristic behavioral change such as an immobile posture, was recognized. We studied the effects of acute stress on levels of 5-hydroxytryptamine (5-HT), histamine (His), gamma aminobutyric acid (GABA) and glutamate (Glu) in different parts of the stress and non-stress rat brain. This stress affected the brain monoamine levels significantly. These results suggest that alterations in levels of brain monoamines after acute immobilization force swim stress are associated with several neurodegenerative and neuropsychiatric diseases and it is capable of altering physiological homeostasis of the body.
\end{abstract}

Keywords: Forced-swimming stress mode; Brain monoamines; 5-HT, GABA; Glutamate; Histamine

\section{Introduction}

Stress can be defined as a brain-body response towards stimuli arising from the environment and internal signals, are interpreted as an interference of homeostasis [1]. A stressful situation is enough to be altered the brain biogenic amines and their levels in the different brain areas including the frontal cortex, thalamus and hypothalamus. Numerous physiological stresses are risk factors for several neuropsychiatric diseases, including depression because it is capable of altering the quality of life of people and has become a major cause of suicidal death [1-6].

Depression is an unbearable neuropsychiatric ailment which is characterized by a pervasive low mood, loss of interest in usual activities, diminished ability to experience pleasure, withdrawal of interest, feelings of worthlessness, and suicidal tendencies
[7-8].Thus, stress is probably the process through which bodybrain integration plays a major role in the balancing of the body integrity. Therefore, the present study has been planned to examine the level of biogenic amine content in different parts of the stress and non-stress rat brain.

This experiments were performed on twenty healthy albino Wistar (AW) rats (with 2 months of age and both genders), weighing 150 to $200 \mathrm{~g}$ from Animal Central House, Institute of Medical Science, Banaras Hindu University, Varanasi, India and were performed in accordance with the Guide for the care and use of laboratory animals, as adopted and promulgated by the Institutional Animal Care Committee of Institute of Medical Science, Banaras Hindu University (Reference number; ECR/526/ Inst/UP/2014Dt.31.1.14).

The rats were housed in polypropylene cages and were

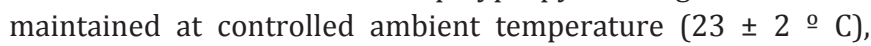
relative humidity (30-70\%) and exposed to $12 \mathrm{~h}$ dark - light cycle and allowed access to food and water ad libtum. This experiment was carried out between 11.00 AM to 5.00 PM and animals were allowed to acclimatize to the laboratory conditions for 7 days prior to dosing.

The rats were used only once for each experiment. The 20 AW rats were equally and randomly assigned in to two groups, namely, Group I: 0.5\% Carboxyl Methyl Cellulose (CMC) plus unstressed (CMC + unstressed), Group II: Water plus immobilize stressed (Immobilization stress an 1 hours every day for 7 days). Rats from the immobilization stressed group were immobilized by fixing a board on their backs for an 1 hour each day for 7 consecutive days. The CMC + unstressed were free of stress. After the end of the experiment the rats were immediately sacrificed by cervical dislocation. The brain was immediately removed and washed with chilled normal saline. Brain were dissected and to obtain frontal cortex, thalamus and hypothalamus. Tissues were 
Table 1: Immobilization stress altered monoamines in brain regions- Frontal cortex, Thalamus and Hypothalamus studied compared to CMC+unstressed rats $(\mathrm{P}<0.05)$.

\begin{tabular}{|c|c|c|c|c|c|c|c|c|c|c|c|c|}
\hline \multirow[b]{2}{*}{ Group } & \multicolumn{4}{|c|}{ Frontal cortex } & \multicolumn{4}{|c|}{ Thalamus } & \multicolumn{4}{|c|}{ Hypothalamus } \\
\hline & $5 \mathrm{HT} \mu \mathrm{g} / \mathrm{g}$ & $\begin{array}{l}\text { His. } \\
\mu \mathrm{g} / \mathrm{g}\end{array}$ & GABA $\mu \mathrm{mol} . / \mathrm{g}$ & Glu. $\mu$ mol./g & $\left\{\begin{array}{l}5 \mathrm{HT} \\
\mu \mathrm{g} / \mathrm{g}\end{array}\right.$ & His. $\mu \mathrm{g} / \mathrm{g}$ & $\begin{array}{l}\text { GABA } \\
\mu \mathrm{mol} . / \mathrm{g}\end{array}$ & Glu. $\mu$ mol./g & g $5 \mathrm{HT} \mu \mathrm{g} / \mathrm{g}$ & His. $\mu \mathrm{g} / \mathrm{g}$ & $\begin{array}{l}\text { GABA } \\
\mu \mathrm{mol} . / \mathrm{g}\end{array}$ & $\begin{array}{l}\text { Glu. } \\
\mu \text { mol./g }\end{array}$ \\
\hline $\begin{array}{l}\text { CMC + } \\
\text { unstressed } \\
\text { rats }\end{array}$ & $1.490 .2 \pm .36^{*}$ & $0.88 \pm .0 .22$ & $3.06 \pm .30 *$ & $16.12 \pm .43^{*}$ & $1.23 \pm .27$ & $1.43 \pm .46$ & $2.18 \pm .31$ & $16.49 \pm .43^{*}$ & $\begin{array}{l}2.89 \pm \\
.50^{*}\end{array}$ & $\begin{array}{l}1.95 \pm \\
.64\end{array}$ & $3.36 \pm .30^{*}$ & $\begin{array}{l}15.21 \pm \\
.26^{*}\end{array}$ \\
\hline $\begin{array}{l}\text { Water plus } \\
\text { immobilize } \\
\text { stressed } \\
\text { rats }\end{array}$ & $0.70 \pm .23$ & $1.98 \pm .42 *$ & $1.91 \pm .29$ & $11 \pm .18$ & $1.03 \pm .19$ & $2.54 \pm .62 *$ & $1.08 \pm .24 \mathrm{c}$ & $11.15 \pm .49$ & $1.45 \pm .31$ & $\begin{array}{l}3.95 \pm \\
.42^{*}\end{array}$ & $1.16 \pm .39$ & $\begin{array}{l}8.23 \pm \\
.27\end{array}$ \\
\hline
\end{tabular}

Table: For Statistical Significance $* \mathrm{P}<0.05,{ }^{* *} \mathrm{P}<0.01,{ }^{* * *} \mathrm{P}<0.001$ in comparison with CMC+unstressed rats.

5HT -Serotonin; His- Histamine; GABA- Gamma-Aminobutyric acid; Glu.-Glutamate

snap frozen in liquid nitrogen and stored at $-80^{\circ} \mathrm{C}$ until analysis $10 \%(\mathrm{~W} / \mathrm{V})$ tissue homogenate was prepared in $0.1 \mathrm{~mol} \cdot \mathrm{L}-1$ phosphate buffer ( $\mathrm{pH}$ 7.4). The homogenates were centrifuged for $15-20 \mathrm{~min}$ at $10000 \mathrm{~g}$ and the supernatants were used for analyses of serotonin and histamine were estimated according to methods described by Snyder (1965) [9] and Shore (1959) [10] respectively. GABA and glutamate estimated by Satio and Tokunaga method (1967) [11].

All data are expressed as mean \pm Standard Error of the Mean (SEM). Data was analyzed using a statistical package (Statistical Package for the Social Sciences (SPSS-16.0). If P value is less than 0.05 , the difference was considered statistically significant. (Table-1).

The maximum 5-HT was found in the hypothalamus region of control brain when compared with frontal cortex and thalamus areas, whereas glutamate was significantly higher in the frontal cortex and thalamus. Immobilized stress was reduced the level of 5-HT and GABA in the frontal cortex, thalamus and hypothalamus in immobilize stressed rats as compared with CMC + unstressed rats (table-1) whereas stress was increased the level of histamine, can significantly increase risk for depression (Suicidal depression) and also associated with insomnia, elevated metabolic rate and higher body temperature. Stress leads to depression, may result in a decreasing in serotonin synthesis.

Adequate level of histamine is important because of the histaminergic neurons act as neurotransmitters, sending their signals throughout the Central Nervous System (CNS), from the spinal cord, brain stem, cerebellum, vestibular nuclei, basal ganglia, amygdala, hippocampus and cerebral cortex [12]. GABA content was significant higher in the frontal cortex and hypothalamus in the CMC + unstressed rats whereas it was highly reduced in the frontal cortex, thalamus and hypothalamus in the stressed rats because of low level of glutamate, is a precursor of GABA. GABA is the principal inhibitory neurotransmitter in the CNS and plays the key role in reducing neuronal excitability throughout the nervous system and responsible for the regulation of muscle tone. Glutamate at the presence of the enzyme L-Glutamic Acid Decarboxylase (GAD) and pyridoxal phosphate (which is the active form of vitamin B6) as a cofactor synthesized GABA in the brain. As we know glutamate is the excitatory neurotransmitter convert into the inhibitory neurotransmitter (GABA) and it is reversible reaction. [13] The present study indicate that stressful life events and chronic stresses are risk factors for several neurodegenerative and neuropsychiatric diseases and it is capable of altering physiological homeostasis of the body and imbalance the neurotransmitter in the brain.

\section{References}

1. Duric V, Clayton S, Leong ML, Yuan LL. Comorbidity Factors and Brain Mechanisms Linking Chronic Stress and Systemic Illness. Neural Plast. 2016;2016:5460732. doi: 10.1155/2016/5460732.

2. Belmaker RH, Agam G. Major depressive disorder. N Engl J Med [Internet]. 2008;358(1):55-68. doi: 10.1056/NEJMra073096.

3. Millan MJ. Multi-target strategies for the improved treatment of depressive states: Conceptual foundations and neuronal substrates. drug discovery and therapeutic application. 2006;110:135-370.

4. Ieraci A, Mallei A, Popoli M. Social Isolation Stress Induces AnxiousDepressive-Like Behavior and Alterations of Neuroplasticity-Related Genes in Adult Male Mice. Neural Plast. 2016;2016:6212983. doi: $10.1155 / 2016 / 6212983$.

5. Liao JC, Tsai JC, Liu CY, Huang HC, Wu LY, Peng WH. Antidepressantlike activity of turmerone in behavioral despair tests in mice. BMC Complement Altern Med. 2013;13:299. doi: 10.1186/1472-6882-13299.

6. Chukwuma ER, Uzoma NO. Flavonoid-rich fraction of the Monodora tenuifolia seed extract attenuates behavioural alterations and oxidative damage in forced-swim stressed rats. Chin J Nat Med. 2015;13(3):183-91.

7. Schechter LE, Ring RH, Beyer CE, Hughes ZA, Khawaja X, Malberg JE, et al. Innovative Approaches for the Development of Antidepressant Drugs: Current and Future Strategies. The American Society for Experimental NeuroTherapeutics, Inc. 2005;2;590-611.

8. Snyder sh, zweig $m$, axelrod $j$, fischer je. Control of the circadian rhythm in serotonin content of the rat pineal gland. Proceedings of the National Academy of Sciences of the United States of America. 1965;53;301-305. 
9. Reis Ede M, Schreiner Neto FW, Cattani VB, Peroza LR, Busanello A Leal CQ, et al. Antidepressant-Like Effect of Ilex paraguariensis in Rats. Biomed Res Int. 2014;2014:958209. doi: 10.1155/2014/958209.

10. Shore P A, Burkhalter A, CohnV H. A methid for fluromateric assay of histamine in tissue. J Pharmacol Exp Ther. 1959;127:182-6.

11. Satio S,Tokunaga Y. some correlation between picrotoxin induced seizures and gamma aminobutyric acid in animal brain.J Pharmacol. Exper.Therp. 1967;157:546-548.
12. Haas HL, Sergeeva OA, Selbach O. Histamine in the Nervous System, Physiological ReviewsJul. 2008;88(3)1183-1241. doi: 10.1152/ physrev.00043.2007.

13. Watanabe M, Maemura K, Kanbara K, Tamayama T, Hayasaki H.GABA and GABA receptors in the central nervous system and other organs. In Jeon KW. Int. Rev. Cytol. International Review of Cytology. 2004;213:1-47. 